J Health Commun. 2016 ; 21(Suppl): 43-50. doi:10.1080/10810730.2015.1131776.

\title{
Health Literacy and Access to Care
}

\author{
Helen Levy, PhD and \\ Research Associate Professor, Institute for Social Research, University of Michigan, Ann Arbor, \\ Ml 48104, (734) $936-4506$
}

\author{
Alex Janke, BS \\ Wayne State University \\ Helen Levy: hlevy@mich.edu; Alex Janke: ajanke@med.wayne.edu
}

\begin{abstract}
Despite well-documented links between low health literacy, low rates of health insurance coverage, and poor health outcomes, there has been almost no research on the relationship between low health literacy and self-reported access to care. This study analyzed a large, nationally representative sample of community-dwelling adults ages 50 and older to estimate the relationship between low health literacy and self-reported difficulty obtaining care. We found that individuals with low health literacy were significantly more likely than individuals with adequate health literacy to delay or forego needed care or to report difficulty finding a provider, even after controlling for other factors including health insurance coverage, employment, race/ethnicity, poverty, and general cognitive function. They were also more likely to lack a usual source of care, although this result was only marginally significant after controlling for other factors. The results show that in addition to any obstacles that low health literacy creates within the context of the clinical encounter, low health literacy also reduces the probability that people get in the door of the health care system in a timely way.
\end{abstract}

\section{Introduction}

The importance of health literacy for a wide range of health-related outcomes - including the use of preventive medical services, control of chronic conditions, and, ultimately, mortality - is well established (Berkman, Sheridan, Donahue, Halpern, \& Crotty, 2011; Paasche-Orlow \& Wolf, 2007; White, Chen, \& Atchison, 2008). However, the mechanisms through which health literacy may affect health outcomes are not well understood (PaascheOrlow \& Wolf, 2007), and there is surprisingly little empirical evidence on how health literacy affects access to care, despite substantial theoretical attention to this question (Sørensen et al., 2012; Squiers, Peinado, Berkman, Boudewyns, \& McCormack, 2012). A recent study establishes that low health literacy is a significant risk factor for lacking health insurance (Sentell, 2012), but almost no research has analyzed whether health literacy is related to self-reported indicators of poor access, including difficulty finding providers, delays in accessing care, or having a usual source of care. 
One reason for this omission may be that, with few exceptions, empirical research on health literacy has relied on samples of individuals who already have an established connection to the health care system. For example, studies have used samples of patients presenting for care at a given clinic (D. W. Baker et al., 2007; Miller, Lee, DeWalt, \& Vann, 2010); patients with a particular condition (Bennett et al., 1998; Grubbs, Gregorich, Perez-Stable, \& Hsu, 2009; Lindau, Basu, \& Leitsch, 2006; Mancuso \& Rincon, 2006); or enrollees in Medicare managed care plans (David W Baker et al., 2004; Cho, Lee, Arozullah, \& Crittenden, 2008; Howard, Gazmararian, \& Parker, 2005; Scott, Gazmararian, Williams, \& Baker, 2002). The use of such samples may understate the negative association between low health literacy and access to care because they do not consider, by design, obstacles that that precede an individual's arrival at a healthcare setting. In a nutshell: if low health literacy keeps individuals from reaching the door of the clinic, then focusing on patients who are already in the door misses a piece of the problem.

The goal of the current study was to explore the relationship between low health literacy and access barriers that arise before individuals get to the clinic door. We used data from a nationally-representative sample of older Americans to estimate the relationship between self-assessed health literacy and four self-reported measures of access to care: (1) delaying care because of cost; (2) delaying care for other reasons; (3) difficulty finding a provider; (4) not having a usual source of care. We also analyzed differences in reported reasons for delaying care and in the nature of difficulty finding a provider.

\section{Study Data and Methods}

\section{Data}

Data for the study come from the Health and Retirement Study (HRS), an ongoing, longitudinal, biennial study of 22,000 individuals ages 51 and older that was begun in 1992, with new sample cohorts enrolled every 6 years. The basic design of the study has been described elsewhere (Juster \& Suzman, 1995; Sonnega et al., 2014a). In addition to the core surveys that are conducted every two years either in person or by telephone to collect information on health, cognition, employment, and economic status, supplemental surveys are administered via US mail or Internet during the off years. We designed such a supplemental survey, with questions on health literacy and access to care, that was administered by mail in fall 2011 to a random subsample of approximately half of the 22,032 individuals who completed the 2010 core survey. We refer to this supplemental survey as the health care mail survey. Most of our key dependent and independent variables came from the health care mail survey, with some covariates drawn from the 2010 core survey.

\section{Sample}

The 2010 HRS sample represents the US population born in 1959 and earlier. Blacks and Hispanics are oversampled by design; the use of analysis weights that address unequal sampling probabilities as well as response rates that vary by racial and geographic subgroups yields nationally representative estimates (Heeringa \& Connor, 1995; Ofstedal, Weir, Chen, $\&$ Wagner, 2011). Response rates to recent waves of the core survey have been above $88 \%$ 
(Sonnega et al., 2014b). Interviews were conducted in English (94\% of the core 2010 sample) and Spanish (6\%). Although the possibility of nonrandom attrition from the sample is a concern for any longitudinal study, several careful studies have documented that attrition bias in the HRS is not significant (Cheshire, Ofstedal, Scholes, \& Schröder, 2011; Weir, Faul, \& Langa, 2011).

The 2011 health care mail survey was sent to a subsample of 10,230 respondents randomly drawn from the 22,032 respondents who completed the 2010 HRS core interview. Seventyfive percent $(n=7,648)$ returned a completed mail survey; of these, we kept the 7,258 who were born before 1960 and therefore age-eligible for the study. We further excluded 23 individuals residing in nursing homes and 93 who did not complete key health literacy and/or access items for a final analysis sample of 7,142 community-dwelling individuals ages and older.

\section{Variables}

Access/utilization-We used four measures of self-reported access to care from the health care mail survey. Respondents were asked whether there was any time in the last twelve months when they needed medical care but did not get it because they couldn't afford it; they were then asked about whether care was ever delayed in the past 12 months for any other reason, with a list of possible reasons where respondents were asked to mark all that apply. We used these responses to construct two measures of delayed care: first, a variable equal to one if the respondent delayed care because of cost, and second, a variable equal to one if the respondent delayed care for some other reason. The third measure was difficulty finding a provider; respondents were asked whether they had any difficulty in the past 12 months finding a general doctor, specialist, or other provider (dentist, physical therapist, occupational therapist, home care provider, pharmacist, other) who would see them, with a list of possible reasons for the difficulty where respondents were asked to mark all that apply. Fourth, respondents were asked whether there is a place they usually go when they are sick or need advice about health; respondents who said "yes" were asked about what kind of place it is. Respondents who reported that there is not a place they usually go, or who report that the place they usually go is a hospital emergency room, were considered to lack a usual source of care.

Health literacy-We measured health literacy using responses to a question included in the health care mail survey: "How confident are you filling out medical forms by yourself?" Possible responses were: extremely confident; quite confident; somewhat confident; a little confident; not at all confident. Studies validating this measure against well-established measures of health literacy such as the Rapid Estimate of Adult Literacy in Medicine (REALM) and the Test of Functional Health Literacy in Adults (TOFHLA) suggest defining low health literacy as a response of "somewhat confident" or less (L. D. Chew, Bradley, \& Boyko, 2004; Lisa D. Chew et al., 2008; Powers, Trinh, \& Bosworth, 2010; Wallace, Rogers, Roskos, Holiday, \& Weiss, 2006) and we followed this convention. This measure has also been validated in Spanish (Sarkar, Schillinger, López, \& Sudore, 2011). 
Health insurance-The health care mail survey asked respondents to report all sources of health insurance - Medicare, Medicaid, employer-sponsored coverage, individually purchased private coverage, TRICARE/CHAMPUS/CHAMPVA, other public coverage, care through the VA - and we created a binary indicator for those with no coverage. Given the documented relationship between health insurance and problems with access to care (Baicker et al., 2013; D. Card, C. Dobkin, \& N. Maestas, 2008; Sommers, Baicker, \& Epstein, 2012) and between low health literacy and health insurance (Sentell, 2012), we considered health insurance status to be a very important control variable for multivariate models.

Health status and chronic conditions-In the mailer survey, respondents reported their health status as excellent, very good, good, fair, or poor; we constructed a binary indicator for fair or poor health. We also used self-reports from the 2010 core HRS to create indicators for respondents who have ever been diagnosed with any of the following chronic conditions: hypertension, diabetes, cancer, lung disease, heart disease, stroke, or psychiatric problems.

Cognition-The core HRS routinely includes a battery of cognition measures, including subtraction ( 7 from 100 successively; 1 from 20 or 1 from 86 , successively), and memory (immediate and delayed recall of a list of common words). These variables provide an observed, rather than self-reported, measure of cognitive ability that has been validated (Langa, Kabeto, \& Weir, 2010). Following a previous study, we defined cognitive impairment as a score of 7 or lower on a 27-point cognition scale constructed using these measures from the core 2010 data (Crimmins, Kim, Langa, \& Weir, 2011). General cognition is highly correlated with health literacy and, if omitted from multivariate analyses, may yield misleadingly large coefficients on health literacy (David W Baker, Wolf, Feinglass, \& Thompson, 2008; Mõttus et al., 2014; Serper et al., 2014).

Demographic and socioeconomic characteristics-The core HRS routinely collects information from all core respondents on age, gender, marital status, race, Hispanic ethnicity, educational attainment, and employment status (full-time work; part-time work; unemployed; retired; neither working nor looking for work). We characterized race and ethnicity using four mutually exclusive categories: white non-Hispanic, black non-Hispanic, other non-Hispanic, and Hispanic (any race). We coded educational attainment categorically: less than high school, high school graduate, some college, and education greater than or equal to a four-year college degree. We include these characteristics in our multivariate models because existing research shows that low health literacy is correlated with age, race, and education (Kutner, Greenberg, Jin, Paulsen \& White 2006).

Statistical methods and analytic approach: All statistical analyses were performed using Stata version 14 (Stata Corporation, College Station, TX) and are weighted to be nationally representative of community-dwelling Americans aged 50 and older. Our statistical analysis began with calculating the average characteristics of participants in our sample and testing for differences in these characteristics across groups defined by low and adequate health literacy, using adjusted Wald tests that take into account the complex 
sampling design of the Health and Retirement Study; we report the p-values associated with these tests. Next, we performed similar tests for differences in the outcomes of interest (access problems; all measured as binary variables) across the two groups, as well as differences in the fraction of participants who reported specific reasons for encountering particular access problems. Our next step was to estimate a multivariate logistic regression for each of the outcomes of interest, modeling these outcomes as function of the covariates described above. The results of the regressions are reported as odds ratios, with associated 95\% confidence intervals that take into account the complex survey design. Finally, in order to provide a meaningful interpretation of the odds ratios from the multivariate models, we calculated the average marginal effect of low health literacy on each outcome by subtracting the average predicted value from the model with "low health literacy" set to equal one from the average predicted value with "low health literacy" set equal to zero. For each outcome, we added this marginal effect to the simple mean value of the outcome for individuals with adequate health literacy to obtain a "covariate-adjusted" estimate of the mean value of each outcome for those with low health literacy. These covariate-adjusted estimates are presented graphically in a figure with the unadjusted mean outcomes for both groups, in order to provide a visual summary of the main results of the analysis.

\section{Study Results}

Table 1 reports average characteristics for participants in our sample with low versus adequate health literacy. Approximately one-quarter of our sample had low health literacy; exact proportions were $24.20 \%$ (weighted) and $26.90 \%$ (unweighted). Consistent with previous research (Sentell, 2012), those with low health literacy were more likely to be uninsured, with $10.49 \%$ uninsured among those with low health literacy compared with only $7.48 \%$ for those with adequate health literacy, a difference that is marginally statistically significant with $\mathrm{p}=0.079$. Individuals with low health literacy were, on average, less educated, more likely to be racial or ethnic minorities, less healthy, older, and more likely to exhibit cognitive impairment than were those with adequate health literacy; these results, too, are also consistent with earlier research (Baker, Gazmararian, Sudan \& Patterson 2000; Baker, Wolf, Feinglass \& Thompson 2008; Kutner, Greenberg, Jin, Paulsen \& White 2006).

Table 2 presents the fraction of individuals who reported having delayed care. About onethird (31.86\%) of those with low health literacy reported that they delayed care in the last 12 months, either because of cost (12.77\%) or for another reason (26.19\%). (Note that these two fractions sum to more than $31.86 \%$ because some people report both cost-related and non-cost-related delays.) In contrast, less than one-quarter (22.98\%) of those with adequate health literacy reported that they delayed or did not obtain care, a significantly lower fraction than among those with low health literacy. Those with adequate health literacy were significantly less likely than those with low health literacy to report either cost-related or non-cost-related problems.

When we looked at the detailed reasons participants offered for delaying care, we found that these reasons differed for participants with low versus adequate health literacy (bottom panel of Table 2). The commonest reason reported for delay by either group was "I could not afford it," reported by $40.09 \%$ those with low health literacy and $34.75 \%$ of those with 
adequate health literacy. The second most common reason overall, "I am too busy to go to the doctor," was reported more than twice as often among respondents with adequate health literacy compared with those who had low health literacy (24.34\% versus $10.61 \%$ ), which likely reflects in part the fact that individuals with low health literacy in our sample were less likely to work than those with adequate health literacy. Three other reasons stand out because they were significantly more likely to be chosen by respondents with low health literacy: not having transportation, having to wait too long at the doctor's office, and being afraid of what they might find out. Almost three times as many respondents with low health literacy reported having delayed care because they did not have transportation (16.88\% versus $6.21 \%$ ). Respondents with low health literacy were significantly more likely to say they had to wait too long once they got to the doctor's office (17.63\% of respondents with low health literacy compared with $10.99 \%$ of those with adequate health literacy). This may have been because they frequented different providers who did, in fact, have longer waiting times or it may have been that individuals with low health literacy had less patience for waiting to see providers, but we could not test those theories using these data. Respondents with low health literacy were also more likely to report that they were afraid of what they might find out. Other reasons for delaying or foregoing care - including not being able to get an appointment soon enough and not being able to get through on the phone - were equally common for respondents with low versus adequate health literacy.

Table 3 presents the fraction of participants who report each of the other access problems we analyze: difficulty finding a provider, not having a usual source of care, and not having had a doctor's visit in the past year. Individuals with low health literacy were also significantly more likely to report difficulty finding a provider (17.09\% for those with low health literacy versus $7.99 \%$ for those with adequate health literacy) or to lack a usual source of care (26.93\% versus $18.47 \%)$. They were also more likely to report not having seen a doctor in the past year, although this difference is not statistically significant at conventional levels ( $\mathrm{p}$ $=0.190$ ). The bottom panel of Table 3 shows reported reasons for difficulty finding a provider, which for the most part were similar for low and adequate health literacy although the prevalence of insurance-related problems - high for both groups - is somewhat higher for individuals with low health literacy $(52.77 \%$ versus $45.96 \%$; $\mathrm{p}=0.071)$. "No appointments available" was the second most common reason for delay, reported by just over 40 percent of those with difficulty regardless of health literacy, and about 20 percent of each group reported not having doctors near where they lived.

For the four access problems that were significantly more likely, in our univariate analyses, to be reported by individuals with low health literacy compared to those with adequate health literacy, we estimated multivariate models to determine whether these differences in reported access could be explained by the differences in other characteristics documented in Table 1. Table 4 presents the results of these multivariate models, which control for insurance status, demographics, socio-economic status, cognitive ability, and health status. Three of the four outcomes - both cost-related and other delays in obtaining care, and difficulty finding a provider - remain significantly more likely among participants with low health literacy compared with participants who have adequate health literacy, after controlling for other characteristics, as indicated in Table 4 by odds ratios and associated 95\% confidence intervals on "low health literacy" that are greater than one. The p-values 
associated with the coefficient on low health literacy in these three models are 0.024 , less than 0.001 , and 0.054 , respectively. For the fourth outcome, no usual source of care, the effect of health literacy is marginally significant $(p=0.080)$ after controlling for other characteristics. These results confirm the significance of low health literacy as a predictor of access problems, even after multiple other factors correlated with low health literacy have been taken into account, including health insurance.

Figure 1 summarizes graphically the main results from our analysis. The blue bars and the red bars represent the rates at which four access problems are reported by participants with adequate health literacy and low health literacy, respectively; these results were also reported in Table 1. The green bars reflect the covariate-adjusted rates of these problems for participants with low health literacy, calculated as described above using the average marginal effect of health literacy on each outcome from the multivariate models. This figure shows the bottom line: access problems - delaying care, difficulty finding a provider, and not having a usual source of care - were more prevalent among individuals with low health literacy, and these disparities persisted even after controlling for other factors.

\section{Study Limitations}

Our study had both strengths and weaknesses. Strengths included the focus on a topic that has received surprisingly little attention from researchers, the use of a nationally representative sample (in contrast to most studies of health literacy), the use of a validated and widely used measure of self-assessed health literacy, and the availability of a rich set of covariates, including general cognitive ability.

A significant limitation of our study was its cross-sectional, observational nature. Although our multivariate analyses include a wide range of relevant covariates, it is possible that an omitted variable correlated with both health literacy and our measures of access to care was driving the apparent correlation between the two. Patient activation, for example, is not measured in our sample, and has been shown to be correlated with both health literacy and health-related outcomes, prompting a debate about the distinctions between these two constructs and their relative importance (Hibberd, Stockard, Mahoney, \& Tusler, 2004; Smith, Curtis, Wardle, von Wagner, \& Wolf, 2013). The possibility of an important omitted variable suggests that our results should not be viewed as the final word on the topic of health literacy and access to care (a position we are inclined to agree with under any circumstances), but rather as highlighting an area where further investigation is needed

Another limitation was the fact that the sample was restricted to individuals aged 50 and older; this study therefore does not speak to the relationship between low health literacy and access to care at earlier stages in the life course. Finally, a limitation related to the use of self-reported measures of access was that we could say relatively little about whether the differences in access that we observed for individuals with low versus adequate health literacy were driven by underlying differences in the actual availability of care or by a similar level of availability that individuals with low health literacy perceived or navigated differently. 


\section{Discussion}

Health literacy matters for access to care. Individuals with low health literacy are more likely to delay getting care and have more difficulty finding providers than their counterparts with adequate health literacy, even after controlling for insurance status and other characteristics. These barriers compound any subsequent difficulties that patients with low health literacy may face in terms of understanding and acting on information from clinical encounters.

Understanding exactly why health literacy matters for access, and how this information should inform interventions to improve outcomes for individuals with low health literacy, is the challenge that remains. One promising avenue may focus on how low health literacy affects individuals' ability to choose or navigate insurance plans. We found that even after controlling for insurance status, individuals with low health literacy report more difficulty finding providers who will see them. This may be because they have insurance coverage that is systematically less generous than do individuals with higher health literacy (for example, narrower provider networks); or it may be that, even with identical insurance coverage, those with low health literacy have more difficulty figuring out which type of provider they need to see, which ones are actually taking new patients, etc. - in short, the hassles that anyone who uses the U.S. health care system is familiar with, but that may loom larger for individuals with low health literacy. The relatively new concept of "health insurance literacy" (Kim, Braun, \& Williams, 2013; McCormack, Bann, Uhrig, Berkman, \& Rudd, 2009; Paez, Mallery, Noel, Pugliese, McSorley, Lucado, \& Ganachari, 2014) encompasses both of these mechanisms. Our results suggest that lower rates of health insurance coverage are not the only reason individuals with low health literacy experience worse access, but this does not mean that health insurance is irrelevant. The interaction between low health literacy and health insurance offers a promising avenue for understanding why individuals with low health literacy are more likely to experience access problems.

Second, our results suggest that interventions to improve outcomes for health literacy should look beyond the clinical encounter to reach individuals for whom low health literacy represents a fundamental obstacle to accessing the health care system. A recent review of interventions for individuals with low health literacy concluded that there has been progress in the range of endpoints targeted by these interventions, with an increasing number moving beyond comprehension of health information as the outcome of interest and looking instead at more distal outcomes such as health (Sheridan, Halpern, Viera, Berkman, Donahue, \& Crotty, 2011). Our results suggest focusing on the middle range as well; can we develop interventions that effectively connect individuals with low health literacy with available providers, and would this then reduce their delays in obtaining care?

Finally, understanding the full implications of low health literacy for access to care will also require a shift in how researchers think about data for studying health literacy. Many studies of health literacy have relied on clinic or disease-based samples, and this approach has yielded important insights into how health literacy affects patient-provider communication in the context of the clinical encounter (Aboumatar, Carson, Beach, Roter, \& Cooper, 2013; Barragan et al., 2005; Katz, Jacobson, Veledar, \& Kripalani, 2007; Mancuso \& Rincon, 
2006; Rodríguez et al., 2013). But a full understanding of the impact of health literacy requires a broader view: one that takes into account the importance of health literacy outside the clinical encounter. Theoretical frameworks for understanding the interaction between health literacy, health care access, and health outcomes encompass multiple factors such as culture, social support, and community health care resources (Squiers et al., 2012).

Addressing unanswered questions about access baiers that arise even before patients reach the clinic will require integrating measures of health literacy into population-based data collection.

\section{Acknowledgments}

Levy acknowledges financial support from the National Institute on Aging (grant number NIA K01AG034232). The data used in this study are from the Health and Retirement Study (HRS), which is sponsored by the National Institute on Aging (grant number NIA U01AG009740) and conducted by the University of Michigan. Preliminary results from this analysis were presented at the 5th Health Literacy Annual Research Conference (HARC V), October 28-29, 2013 in Washington, DC.

\section{References}

Aboumatar HJ, Carson KA, Beach MC, Roter DL, Cooper LA. The Impact of Health Literacy on Desire for Participation in Healthcare, Medical Visit Communication, and Patient Reported Outcomes among Patients with Hypertension. Journal of General Internal Medicine. 2013; 28(11): 1469-1476. [PubMed: 23690237]

Baicker K, Taubman SL, Allen HL, Bernstein M, Gruber JH, Newhouse JP, ... Finkelstein AN. The Oregon experiment - effects of Medicaid on clinical outcomes. New England Journal of Medicine. 2013; 368(18):1713-1722. [PubMed: 23635051]

Baker DW, Gazmararian JA, Sudano J, Patterson M. The association between age and health literacy among elderly persons. The Journals of Gerontology Series B: Psychological Sciences and Social Sciences. 2000; 55(6):S368-S374.

Baker DW, Gazmararian JA, Williams MV, Scott T, Parker RM, Green D, ... Peel J. Health literacy and use of outpatient physician services by Medicare managed care enrollees. Journal of General Internal Medicine. 2004; 19(3):215-220. [PubMed: 15009775]

Baker DW, Wolf MS, Feinglass J, Thompson JA. Health literacy, cognitive abilities, and mortality among elderly persons. J Gen Intern Med. 2008; 23(6):723-726. [PubMed: 18330654]

Baker DW, Wolf MS, Feinglass J, Thompson JA, Gazmararian JA, Huang J. Health literacy and mortality among elderly persons. Archives of Internal Medicine. 2007; 167(14):1503-1509. DOI: 10.1001/archinte.167.14.1503 [PubMed: 17646604]

Barragan M, Hicks G, Williams MV, Franco-Paredes C, Duffus W, Del Rio C. Low health literacy is associated with HIV test acceptance. Journal of General Internal Medicine. 2005; 20(5):422-425. [PubMed: 15963165]

Bennett CL, Ferreira MR, Davis TC, Kaplan J, Weinberger M, Kuzel T, ... Sartor O. Relation between literacy, race, and stage of presentation among low-income patients with prostate cancer. Journal of Clinical Oncology. 1998; 16(9):3101-3104. [PubMed: 9738581]

Berkman ND, Sheridan SL, Donahue KE, Halpern DJ, Crotty K. Low Health Literacy and Health Outcomes: An Updated Systematic Review. Annals of Internal Medicine. 2011; 155(2):97-107. DOI: 10.7326/0003-4819-155-2-201107190-00005 [PubMed: 21768583]

Card D, Dobkin C, Maestas N. The Impact of Nearly Universal Insurance Coverage on Health Care Utilization: Evidence from Medicare. Am Econ Rev. 2008; 98(5):2242-2258. [PubMed: 19079738]

Card D, Dobkin C, Maestas N. The Impact of Nearly Universal Insurance Coverage on Health Care Utilization: Evidence from Medicare. American Economic Review. 2008; 98(5):2242-2258. [PubMed: 19079738] 
Cheshire H, Ofstedal MB, Scholes S, Schröder M. A comparison of response rates in the English Longitudinal Study of Ageing and the Health and Retirement Study. Longitudinal and Life Course Studies. 2011; 2(2):127. [PubMed: 24432049]

Chew LD, Bradley KA, Boyko EJ. Brief questions to identify patients with inadequate health literacy. Fam Med. 2004; 36(8):588-594. [PubMed: 15343421]

Chew LD, Griffin JM, Partin M, Noorbaloochi S, Grill JP, Snyder A, ... VanRyn M. Validation of Screening Questions for Limited Health Literacy in a Large VA Outpatient Population. Journal of General Internal Medicine. 2008; 23(5):561-566. DOI: 10.1007/s11606-008-0520-5 [PubMed: 18335281]

Cho YI, Lee SYD, Arozullah AM, Crittenden KS. Effects of health literacy on health status and health service utilization amongst the elderly. Social science \& medicine. 2008; 66(8):1809-1816. [PubMed: 18295949]

Crimmins EM, Kim JK, Langa KM, Weir DR. Assessment of cognition using surveys and neuropsychological assessment: the health and retirement study and the aging, demographics, and memory study. The Journals of Gerontology Series B: Psychological Sciences and Social Sciences. 2011; 66(suppl 1):i162-i171.

Grubbs V, Gregorich SE, Perez-Stable EJ, Hsu C-y. Health literacy and access to kidney transplantation. Clinical Journal of the American Society of Nephrology. 2009; 4(1):195-200. [PubMed: 19056617]

Heeringa, SG.; Connor, JH. Technical description of the Health and Retirement Survey sample design. Ann Arbor: University of Michigan; 1995.

Hibbard JH, Stockard J, Mahoney ER, Tusler M. Development of the Patient Activation Measure (PAM): conceptualizing and measuring activation in patients and consumers. Health services research. 2004; 39(4p1):1005-1026. [PubMed: 15230939]

Howard DH, Gazmararian J, Parker RM. The impact of low health literacy on the medical costs of Medicare managed care enrollees. The American journal of medicine. 2005; 118(4):371-377. [PubMed: 15808134]

Juster FT, Suzman R. An Overview of the Health and Retirement Study. The Journal of Human Resources. 1995; 30:S7-S56. (ArticleType: research-article / Issue Title: Special Issue on the Health and Retirement Study: Data Quality and Early Results / Full publication date: 1995 / Copyright (C) 1995 The Board of Regents of the University of Wisconsin System). DOI: $10.2307 / 146277$

Katz MG, Jacobson TA, Veledar E, Kripalani S. Patient literacy and question-asking behavior during the medical encounter: a mixed-methods analysis. J Gen Intern Med. 2007; 22(6):782-786. [PubMed: 17431697]

Kim J, Braun B, Williams AD. Understanding health insurance literacy: A literature review. Family and Consumer Sciences Research Journal. 2013; 42(1):3-13.

Kutner, M.; Greenburg, E.; Jin, Y.; Paulsen, C. The Health Literacy of America's Adults: Results from the 2003 National Assessment of Adult Literacy. National Center for Education Statistics; 2006. NCES 2006-483

Langa K, Kabeto M, Weir D. Report on race and cognitive impairment using HRS in, 2010 Alzheimer's disease facts and figures. 2010 Retrieved July 12, 2010.

Lindau ST, Basu A, Leitsch SA. Health Literacy as a Predictor of Follow-Up After an Abnormal Pap Smear: A Prospective Study. Journal of General Internal Medicine. 2006; 21(8):829-834. [PubMed: 16881942]

Mancuso CA, Rincon M. Impact of health literacy on longitudinal asthma outcomes. Journal of General Internal Medicine. 2006; 21(8):813-817. [PubMed: 16881939]

McCormack L, Bann C, Uhrig J, Berkman N, Rudd R. Health insurance literacy of older adults. Journal of Consumer Affairs. 2009; 43(2):223-248.

Miller E, Lee JY, DeWalt DA, Vann WF. Impact of caregiver literacy on children's oral health outcomes. Pediatrics. 2010; 126(1):107-114. [PubMed: 20547644]

Mõttus R, Johnson W, Murray C, Wolf MS, Starr JM, Deary IJ. Towards understanding the links between health literacy and physical health. Health Psychology. 2014; 33(2):164. [PubMed: 23437854] 
Ofstedal, M.; Weir, D.; Chen, K.; Wagner, J. Updates to HRS Sample Weights. Ann Arbor: University of Michigan; 2011.

Paasche-Orlow MK, Wolf MS. The causal pathways linking health literacy to health outcomes. American Journal of Health Behavior. 2007; 31(Supplement 1):S19-S26. [PubMed: 17931132]

Paez KA, Mallery CJ, Noel H, Pugliese C, McSorley VE, Lucado JL, Ganachari D. Development of the Health Insurance Literacy Measure (HILM): Conceptualizing and measuring consumer ability to choose and use private health insurance. Journal of health communication. $2014 ; 19(\sup 2): 225-$ 239. [PubMed: 25315595]

Powers BJ, Trinh JV, Bosworth HB. Can this patient read and understand written health information? JAMA. 2010; 304(1):76-84. DOI: 10.1001/jama.2010.896 [PubMed: 20606152]

Rodríguez V, Andrade AD, García-Retamero R, Anam R, Rodríguez R, Lisigurski M, ... Ruiz JG. Health Literacy, Numeracy, and Graphical Literacy Among Veterans in Primary Care and Their Effect on Shared Decision Making and Trust in Physicians. J Health Commun. 2013; 18(sup1): 273-289. [PubMed: 24093361]

Sarkar U, Schillinger D, López A, Sudore R. Validation of Self-Reported Health Literacy Questions Among Diverse English and Spanish-Speaking Populations. Journal of General Internal Medicine. 2011; 26(3):265-271. DOI: 10.1007/s11606-010-1552-1 [PubMed: 21057882]

Scott TL, Gazmararian JA, Williams MV, Baker DW. Health literacy and preventive health care use among Medicare enrollees in a managed care organization. Medical care. 2002; 40(5):395-404. [PubMed: 11961474]

Sentell T. Implications for reform: Survey of California adults suggests low health literacy predicts likelihood of being uninsured. Health Affairs. 2012; 31(5):1039-1048. [PubMed: 22566444]

Serper M, Patzer RE, Curtis LM, Smith SG, O'Conor R, Baker DW, Wolf MS. Health Literacy, Cognitive Ability, and Functional Health Status among Older Adults. Health Services Research. 2014

Sheridan SL, Halpern DJ, Viera AJ, Berkman ND, Donahue KE, Crotty K. Interventions for individuals with low health literacy: a systematic review. Journal of health communication. 2011; 16(sup3):30-54. [PubMed: 21951242]

Smith SG, Curtis LM, Wardle J, von Wagner C, Wolf MS. Skill set or mind set? Associations between health literacy, patient activation and health. PLoS One. 2013; 8(9):e74373. [PubMed: 24023942]

Sommers BD, Baicker K, Epstein AM. Mortality and Access to Care among Adults after State Medicaid Expansions. New England Journal of Medicine. 2012; 367(11):1025-1034. DOI: 10.1056/NEJMsa1202099 [PubMed: 22830435]

Sonnega A, Faul JD, Ofstedal MB, Langa KM, Phillips JW, Weir DR. Cohort Profile: the Health and Retirement Study (HRS). International journal of epidemiology. 2014a; 43(2):576-585. [PubMed: 24671021]

Sonnega A, Faul JD, Ofstedal MB, Langa KM, Phillips JWR, Weir DR. Cohort Profile: the Health and Retirement Study (HRS). International Journal of Epidemiology. 2014b; doi: 10.1093/ije/dyu067

Sørensen K, Van den Broucke S, Fullam J, Doyle G, Pelikan J, Slonska Z, Brand H. Health literacy and public health: a systematic review and integration of definitions and models. BMC Public Health. 2012; 12(1):80. [PubMed: 22276600]

Squiers L, Peinado S, Berkman N, Boudewyns V, McCormack L. The health literacy skills framework. J Health Commun. 2012; 17(sup3):30-54. [PubMed: 23030560]

Wallace LS, Rogers ES, Roskos SE, Holiday DB, Weiss BD. BRIEF REPORT: Screening Items to Identify Patients with Limited Health Literacy Skills. Journal of General Internal Medicine. 2006; 21(8):874-877. DOI: 10.1111/j.1525-1497.2006.00532.x [PubMed: 16881950]

Weir DR, Faul JD, Langa KM. Proxy interviews and bias in cognition measures due to non-response in longitudinal studies: a comparison of HRS and ELSA. Longitudinal and Life Course Studies. 2011; 2(2):170-184. [PubMed: 25360159]

White S, Chen J, Atchison R. Relationship of preventive health practices and health literacy: a national study. American Journal of Health Behavior. 2008; 32(3):227-242. [PubMed: 18067463] 


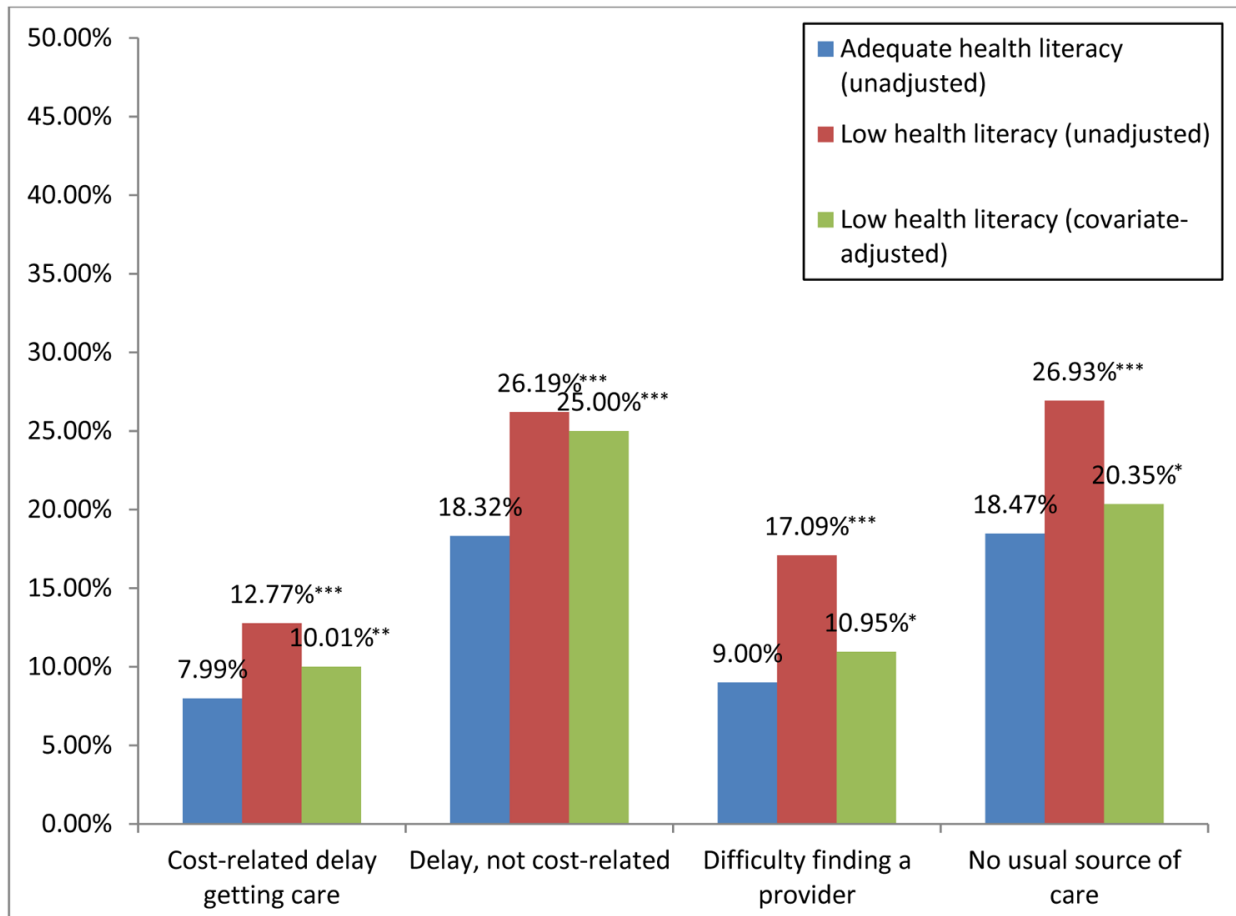

Figure 1.

Rates of self-reported access problems among individuals with low versus adequate health literacy, unadjusted and adjusted for covariates

Notes. Asterisks indicate a rate that is significantly different from the rate for individuals with adequate health literacy, with $\mathrm{p}<0.01(* * *), \mathrm{p}<0.05(* *)$, or $\left.\mathrm{p}<0.10{ }^{*}\right)$. Please see the text for a description of how covariate-adjusted rates are calculated. 


\section{Table 1}

Participant characteristics, by health literacy status

\begin{tabular}{lccc}
\hline & \multicolumn{3}{c}{ Health literacy } \\
\cline { 2 - 4 } & Low & Adequate & $\boldsymbol{p}$ value \\
\hline Characteristic & $10.49 \%$ & $7.48 \%$ & 0.079 \\
\hline No health insurance & 11.3 & 13.8 & $<0.001$ \\
Years of education & $71.03 \%$ & $84.85 \%$ & $<0.001$ \\
White non-Hispanic & $10.72 \%$ & $6.70 \%$ & $<0.001$ \\
African-American non-Hispanic & $3.48 \%$ & $3.36 \%$ & 0.888 \\
Other non-Hispanic & $14.77 \%$ & $5.09 \%$ & $<0.001$ \\
Hispanic (any race) & 66.7 & 63.8 & $<0.001$ \\
Age (years) & $48.92 \%$ & $56.37 \%$ & $<0.001$ \\
Female & $61.36 \%$ & $69.56 \%$ & $<0.001$ \\
Married & $28.37 \%$ & $45.77 \%$ & $<0.001$ \\
Working & $16.60 \%$ & $5.44 \%$ & $<0.001$ \\
Income less than poverty & $7.70 \%$ & $1.56 \%$ & $<0.001$ \\
Congitive impairment & $48.14 \%$ & $15.07 \%$ & $<0.001$ \\
Health is fair or poor & $81.93 \%$ & $70.88 \%$ & $<0.001$ \\
Has chronic health condition & 1,921 & 5,221 & 7,142 \\
\hline Unweighted $n$ & & & \\
\hline
\end{tabular}

Note. The p value reported in the final column is associated with a test of the null hypothesis that the outcome reported in that row is the same for individuals with low versus adequate health literacy. 
Table 2

Delayed/foregone care, by low vs. adequate health literacy status

\begin{tabular}{lccc}
\hline & \multicolumn{3}{c}{ Health literacy } \\
\cline { 2 - 4 } & Low & Adequate & $\boldsymbol{p}$ value \\
\hline Fraction of participants who reported delaying or not obtaining care... & & \\
\hline ...for any reason & $31.86 \%$ & $22.98 \%$ & $<0.001$ \\
...because of cost & $12.77 \%$ & $7.99 \%$ & $<0.001$ \\
...for a reason other than cost & $26.19 \%$ & $18.32 \%$ & $<0.001$ \\
\hline Among those who delayed or did not obtain care, the fraction who reported each of the following reasons: \\
\hline Could not afford it & $40.09 \%$ & $34.75 \%$ & 0.091 \\
I am too busy to go to the doctor & $10.61 \%$ & $24.34 \%$ & $<0.001$ \\
I don't like going to the doctor & $27.84 \%$ & $22.82 \%$ & 0.153 \\
I couldn't get an appointment soon enough & $18.62 \%$ & $19.38 \%$ & 0.790 \\
I am afraid of what I might find out & $14.37 \%$ & $9.41 \%$ & 0.040 \\
Once I get there, I have to wait too long & $17.63 \%$ & $10.99 \%$ & 0.005 \\
I didn't have transportation & $16.88 \%$ & $6.21 \%$ & $<0.001$ \\
The clinic wasn't open when I could get there & $5.84 \%$ & $6.42 \%$ & 0.690 \\
I couldn't get through on the telephone & $8.77 \%$ & $7.22 \%$ & 0.413 \\
I don't believe in going to doctors & $2.98 \%$ & $2.97 \%$ & 0.988 \\
\hline Unweighted n: all participants & 1,921 & 5,221 & \\
\hline Unweighted n: participants reporting delayed/foregone care & 590 & 1,146 & \\
\hline
\end{tabular}

Notes. Percentages are weighted. The $\mathrm{p}$ value reported in the final column is associated with a test of the null hypothesis that the outcome reported in that row is the same for individuals with low versus adequate health literacy. 


\section{Table 3}

Difficulty finding provider, no usual source of care, and no doctor visit in past year, by low vs. adequate health literacy status

\begin{tabular}{lccc}
\hline & \multicolumn{3}{c}{ Health literacy } \\
\cline { 2 - 4 } & Low & Adequate & $\boldsymbol{p}$ value \\
\hline Fraction of participants who reported... & & & \\
\hline ...difficulty finding a provider & $17.09 \%$ & $9.00 \%$ & $<0.001$ \\
$\ldots$ no usual source of care & $26.93 \%$ & $18.47 \%$ & $<0.001$ \\
$\ldots$ no doctor visit in past year & $10.93 \%$ & $9.35 \%$ & 0.190 \\
\hline Among those who reported difficulty finding a provider, the fraction who reported each of the following reasons: \\
\hline Insurance-related problem & $52.77 \%$ & $45.96 \%$ & 0.071 \\
No appointments available & $42.66 \%$ & $40.59 \%$ & 0.613 \\
No doctors near where I live & $23.18 \%$ & $19.09 \%$ & 0.256 \\
Other & $5.99 \%$ & $5.51 \%$ & 0.817 \\
\hline Unweighted n, all participants & 1,921 & 5,221 & \\
\hline Unweighted n, participants with difficulty finding a provider & 361 & 536 & \\
\hline
\end{tabular}

Notes. Percentages are weighted. The p value reported in the final column is associated with a test of the null hypothesis that the outcome reported in that row is the same for individuals with low versus adequate health literacy. 


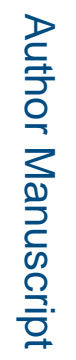

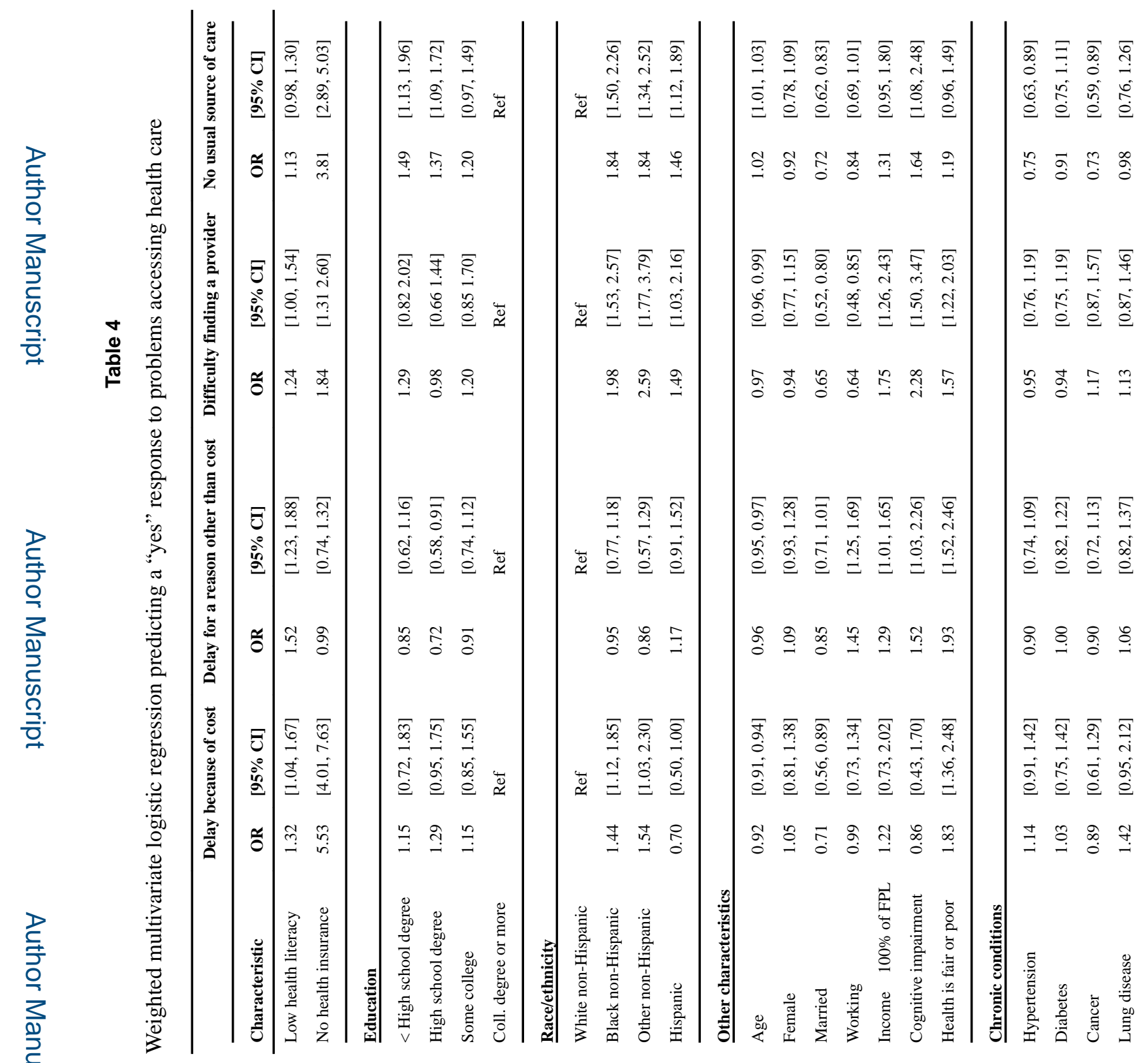

J Health Commun. Author manuscript; available in PMC 2017 January 01. 


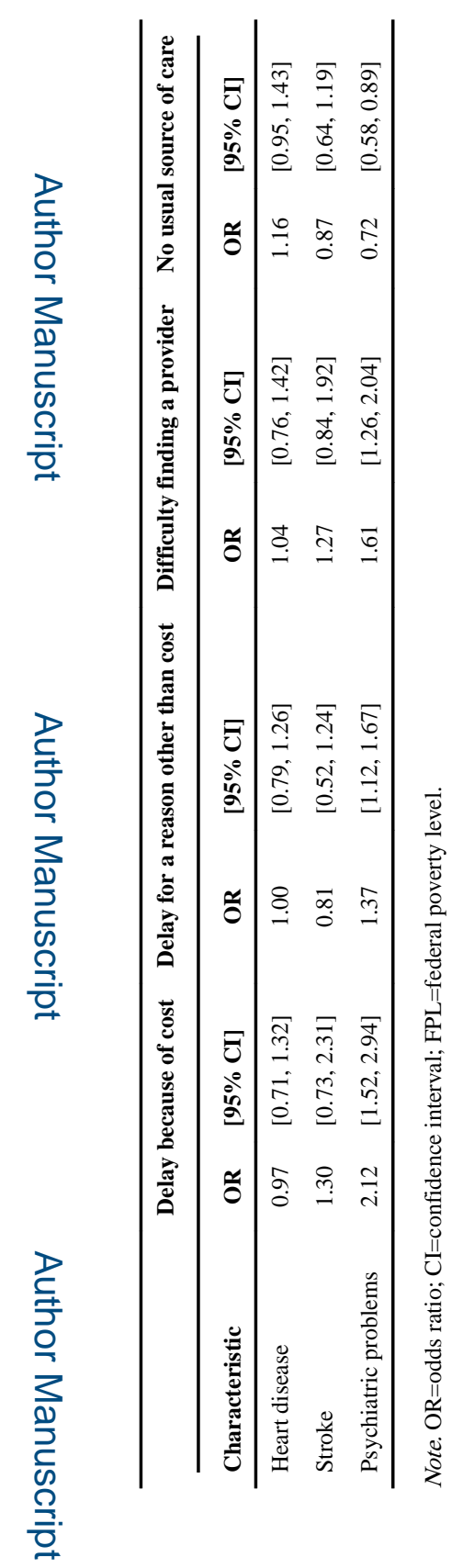

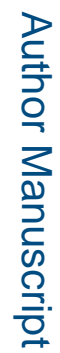

